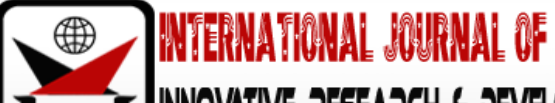 $\chi_{\text {mans }}$ MOOWANE REFARCH 6 DVEOONWENT
}

ISSN 2278-0211 (Online)

\section{A Review of E-Government Models Used in Kenya: Case Study of the University of Nairobi}

\author{
Mulwa, Peter Kyalo \\ Assistant Lecturer, School of Education, University of Nairobi, Nairobi, Kenya
}

\begin{abstract}
E-government models adopted by most countries vary depending on the technology used. The commonly used e-government models in developed and developing countries are Web-based. However, the development of ICT has enormously influenced the way business is conducted in government. This has resulted to adoption of other models that are deemed to be effective and reliable. For instance, proliferation of mobile devices has led to adoption of SMS-based e-government models which are slowly becoming popular among government agencies. This study was a case study to review the e-government models adopted by the University of Nairobi, which is a Government agency in Kenya. The objectives of the study were to establish whether government agencies delivered e-government services, the technology employed in availing and accessing the egovernment service, effectiveness and reliability of the e-government models used in Kenya. Data was collected mainly by use of questionnaires and analyzed using Statistical Package for Social Science (SPSS). Stratified random sampling was used to determine the population from where the research data was collected. The findings were that government agencies in Kenya such as the University of Nairobi offered e-government services, web-based e-government model implemented using websites and email systems is the widely used, however, the systems were ineffective and unreliable. This was attributed to the fact that the systems provided static information, did not provide instant feedback and depends on Internet infrastructure that was poor in the country. It was also found out that SMS-based model was increasingly becoming popular in the country. The study recommended developing of e-government systems that integrate web-based and SMS-based models to enhance effectiveness and reliability, extension of Internet infrastructure country wide, lowering cost of Internet access and carrying further studies on design and development of effective, efficient and reliable e-government models.
\end{abstract}

Keywords: e-government, web-based e-Government model, SMS-based e-government model

\section{Introduction}

The development of ICT has enormously influenced the social, economic and political life pattern in both developed and developing countries. Tony, Goodwin and Paul (2008) opined that governance, democracy and commerce have changed due to the development of information communication and technology (ICT). This indicates that the penetration of ICT in most aspects of human life has led to changes in the way humans interact within the society and the way societies involve individuals in offering or accessing services. Most governments in both developed and developing countries have or are integrating ICT in delivering of services to citizens (G2C), conducting government to government (G2G) and government to business (G2B) businesses. The World Bank (2005) report on e-development defines e-government as "government-owned or operated systems of information and communications technologies (ICTs) that transform relations with citizens, the private sector and/or other government agencies so as to promote citizen empowerment, improve service delivery, strengthen accountability, increase transparency, or improve government efficiency". The World Bank's definition concurs with Layne\& Lee (2001) who opined that e-Government involves serving citizens in public sector via ICT. This implies that e-Government involves integrating technology particularly web-based Internet applications to enhance the access to and delivery of government information and services to citizens; employees; business partners and other government agencies. The main objective is for a government to provide easy and fast accessibility of its services and information to its citizens indicating the need to adopt e-government models that are effective, efficient and reliable.

\subsection{Existing E-Government Models}

There are many e-government models adopted in the developed and developing countries. The most common models are the Web-based and the SMS-based models.

\subsubsection{Web-Based E-Government Models}

Most of the governments offer e-government services through the web-based models mainly through the Internet

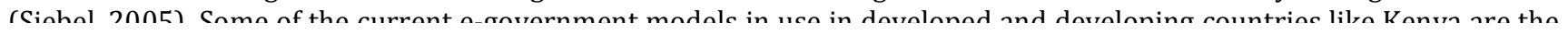


Gartner Model, the Universal Access Model, the Broadcasting/Wider-Dissemination Model, the Interactive Service Model and the Comparative Analysis Model (Backus, 2001). The most commonly used model in the developed and developing countries is the Gartner Model. According to Baum \& Di Maio (2000), Gartner proposed a four-stage model with the stages as the Web presence, Interaction, Transaction and Transformation shown in figure 1 below.

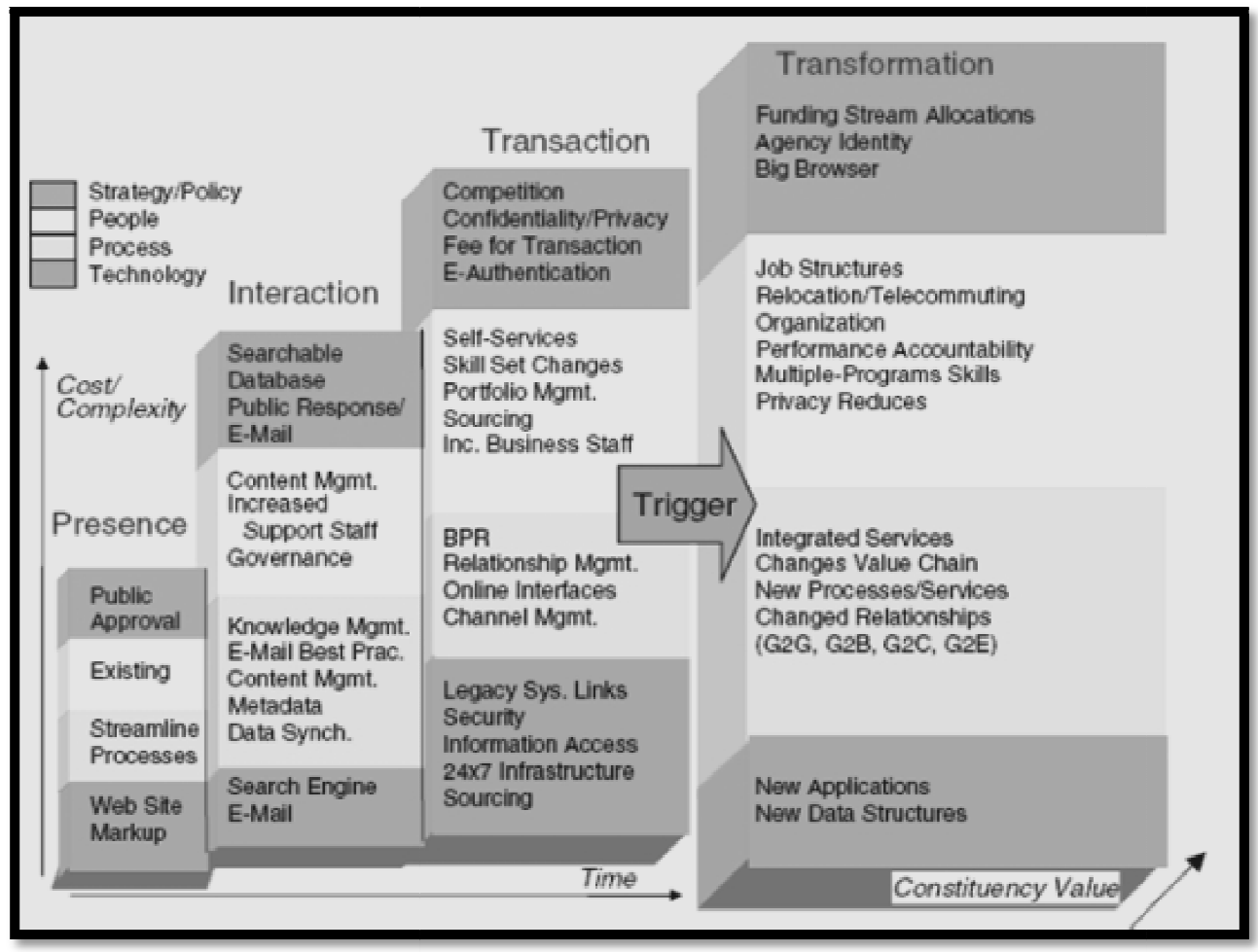

Figure 1: The Gartner E-Government Model (Adopted from Baum and Di Maio, 2000)

At the web presence phase as shown in figure 1 above, agencies provide a web site to post basic information to public for access. At the interaction phase, users contact agencies through web sites (for example through e-mail) or do self-service, for example by downloading documents from the website. At the transaction phase, users can complete entire transactions for example license application and procurement online while at the transformation phase, governments transform the current operational processes to provide more efficient, integrated, unified, and personalized services. The Transformation phase is seen at the regional and national levels, consisting of integration among internal and external applications, in order to provide full communication between the governmental offices and non-governmental organizations.

Backus (2001) opined that the Gartner model can serve as a reference to evaluate where e-government project fits in the overall e-government strategy. However, Backus (2001) points out that this model provides a one-way communication at the transaction phase, where citizens are not guaranteed of feedback after carrying transactions online and that timely response is not guaranteed especially for urgent information from either Government or citizen. Concurring to this, Layne\& Lee (2001) observed that web-based e-government models lack of effectiveness, efficiency, and reliability. Rusdiah (2003) further observed that these models are characterized by static and insufficient information that is infrequently updated, few interactive features, non-existent online service and low citizen participation.

This indicates that adoption of e-government may fail to offer services to citizens effectively and efficiently. Concurring to this, Heeks (2003) identified three critical factors that lead to failure of e-government projects in developing countries as unrealistic design, inadequate technological infrastructure and lack of requisite competencies. According to Ndou (2004) web-based models may not be appropriate in the countries that lack Internet infrastructure, has high Internet costs, low Internet penetration and its citizens are Internet illiterate. For instance, Ndou (2004) observed that in Indonesia, after 5 years implementing e-government using the Gartner model, as of 2003 the success level was just 2\%: 3 out of 169 e-government systems had achieved the Interaction and Transaction levels with $98 \%$ of the local e-government systems operating at the lowest level.

Further, alluding to this, Wang, Bretschneider and Gant (2005) opine that the design of web-based models concentrates on features that would enhance its usability but not how citizens access the information being sought. Susanto \& Goodwin (2006) pointed out that web-based e-government models involving use of Email applications have limitations that include but not limited to security and lack effectiveness. This indicates that a realistic e-government model should be appropriate to the current situation of the country; otherwise there will be a gap between the model and reality. The larger this gap is, the greater the risk that the e-government model adopted will fail. This calls for adoption of technologies that can enhance the web-based models for service delivery backed up by effective and efficient transfer and access to government information. 


\subsubsection{SMS-Based Models}

SMS-based e-government involves the utilization of Short Message Service (SMS) technology, services and applications for improving benefits to the parties involved in e-government including citizens, business, and government institutions. This model utilizes mobile computing technologies where short messages can be used to convey information from one mobile device to another. Susanto \& Goodwin (2007) contend that developing countries, which may lack Internet infrastructure or have expensive internet services but have mobile infrastructure and with citizens who are familiar with mobile phones and SMS, it is appropriate to propose an e-government model that uses mobile phones and SMS as the main communications channel. Susanto \& Goodwin (2010) opine that SMS-based e-government is more likely to increase egovernment usage than the current Internet-based e-government.

Susanto \& Goodwin (2006) proposed a Six-Level Model of SMS-based e-Government. The model suggests that SMS-based e-government services can be classified into six levels based on the service offerings: Listen, Notification, Pull-based Information, Communication, Transaction, and Integration as illustrated in the Figure 2 below.

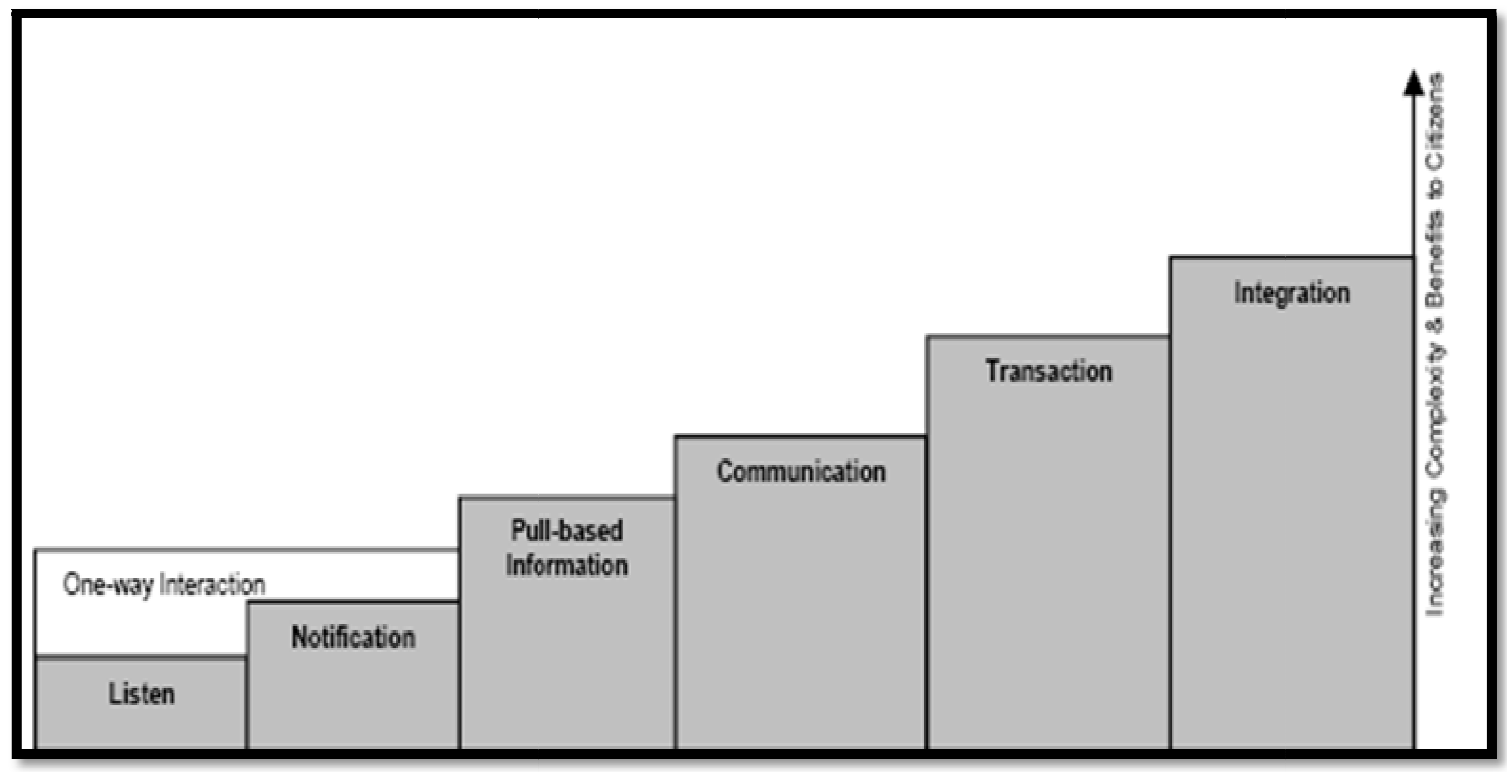

Figure 2: A Six-Level Model of SMS-Based E-Government (Adopted from Susanto, Goodwin\& Paul 2008)

At the Listen level citizens use SMS to send messages directly to government agencies; however, they do not receive a reply since the systems are not designed to reply to the input-messages or to inform the sender of the following actions. This level provides a one-way communication mode from citizens to government. The lack of responsiveness and transparency, as well as protection for the senders' privacy and security prevent the public from actively participating in using these services. At the notification level, current SMS-based e-government systems have enabled one-way communication from government to citizens. The government is able to notify citizens about their personal information and to broadcast important public information. At the pull-based Information level, the current SMS-based e-government systems provide two-way communication that enables citizens to access public or personal information by sending a request-message and a reply service is sent back to the sender's handset via SMS. Some challenges in this level include how to provide cheap or even free notification services (value for money benefit), how to choose the information services which are really needed by citizens (awareness), and how to provide a simple, easy to use and remember request message formats (usability).

At the Communication level some SMS-based e-government systems provide two-way communication between government and citizens in which the people can inquire, complain or report about anything (without worrying about the text format) and get responses/replies immediately. This level affords the users benefits of accessibility, availability, responsiveness, courtesy and helpfulness, usability, timeliness, accountability, and transparency. However, common issues raised at this level include low protection for privacy and security of the senders and lack of the assurance of fast and low responsiveness. At the transaction level some SMS-based e-government systems can process transactions; however, issues of trust and security are dominant. Lastly, at the integration level all the SMS-based systems are integrated and organized in a single portal so people just send messages to a single service number for all services. This level predicts the integrated-SMS systems can also be integrated with the Internet/web-based e-government systems so citizens have options whether accessing the services by sending SMS to one number or through the Internet at one web address.

The use of SMS-based model is not without limitations which include: most mobile devices such as mobile phones allow users to send up to a maximum of 160 words per message; excess information cannot be sent as attachment due to the limited storage capacities of these mobile devices and that most SMS users use abbreviations or symbols that make it difficult for the recipient to comprehend the information conveyed. However, Nonyongo, Mabusela and Monene (2007) opined that the SMS-based e-government model is preferred because it is quick, efficient, cheap and convenient. 


\subsection{Problem Statement}

E-government services in Kenya and in most other developing countries are delivered through the web-based systems. However, majority of citizens have no access to these systems due to poor Internet infrastructure. This deprives off the majority of them their rights of access to government information and services. In situations where citizens have access to Internet connectivity, access to the e-government services and response and feedback from the government or the citizens is usually not timely mostly because majority of them are usually offline or hindered to access the Internet due to its high costs. Further, most of the citizens use basic-feature phones which limit them access to the information shared on websites and email. Owing to this, it was imperative to carry this study to review current e-Government models in use in Kenya to establish whether government agencies deliver services through e-government, the technologies used to deliver and access the services and the effectiveness and reliability of e-government models in use.

\subsection{Purpose of the Study} Nairobi.

The purpose of the study was to review the e-government models used in Kenya: a case study of University of

\subsection{Research Objectives}

The specific objectives were to;

- Establish whether government agencies were delivering e-government services in Kenya

- Establish the technologies accessing e-government service in Kenya

- Determine the effectiveness and efficiency of the e-government models used in Kenya

- Examine the reliability of the e-government models used in Kenya

\section{Methodology}

The methodology employed was a case study to establish whether government agencies were delivering egovernment services, the tools used for communication in these models, their effectiveness and reliability. The study targeted government staff top management, middle level management, teaching staff and support staff working in a government agency, that is University of Nairobi. Data was collected using questionnaire piloted to test for ambiguity and ease of response using few respondents. The validity of the questionnaire was tested by subjecting it to a few respondents. Content validity and relevance was analyzed through peer-review. Statistical package for Social Sciences (SPSS) was used to determine the Cronbach Alpha coefficient of validity. Descriptive statistics was used mainly for analysis of the data. Frequency tables, charts and crosstab tables were used for presentation of the results.

\section{Findings and Discussion}

\subsection{Delivery of E-Government Services}

This study sought to find out whether citizens and government employees in government agencies such as the University of Nairobi are familiar with e-government and e-governance and accessing e-government services as advocated by the government of Kenya and whether e-governance is implemented in their organizations. From the data obtained, most of the respondents indicated that they are familiar with e-government and e-governance. This was evidenced by $50.0 \%$ of the respondents who agreed and $27.4 \%$ strongly agreed to be familiar with the terms e-government and egovernance, see Table 1.

\begin{tabular}{|c|c|c|c|c|c|}
\hline \multicolumn{2}{|c|}{} & & & & \\
\hline Valid & Strongly agree & 23 & 27.4 & 27.4 & CumulativePercent \\
\hline & Agree & 42 & 50.0 & 50.0 & 27.4 \\
\hline & Not Sure & 12 & 14.3 & 14.3 & 77.4 \\
\hline & Disagree & 6 & 7.1 & 7.1 & 91.7 \\
\hline & Strongly disagree & 1 & 1.2 & 1.2 & 98.8 \\
\hline & Total & 84 & 100.0 & 100.0 & 100.0 \\
\hline
\end{tabular}

Table 1: Staff Opinion on Familiarity with E-Government and E-Governance

On whether e-governance is implemented in government agencies like University of Nairobi, the study sought the opinion of the respondents who are familiar with e-governance on whether e-government is being implemented in their organization. The study established that majority of the respondents were aware that e-governance is being implemented in their organization. This was evidenced by $59.5 \%$ of the respondents who indicated to be aware of e-governance in their organization. However, $28.6 \%$ of the respondents disagreed that e-governance is implemented in their organization with $11.9 \%$ indicating to be not aware of e-governance use in their organization as shown in Figure 3 below. This indicates that there should be a deliberate effort to create awareness of e-government services in Kenya. 


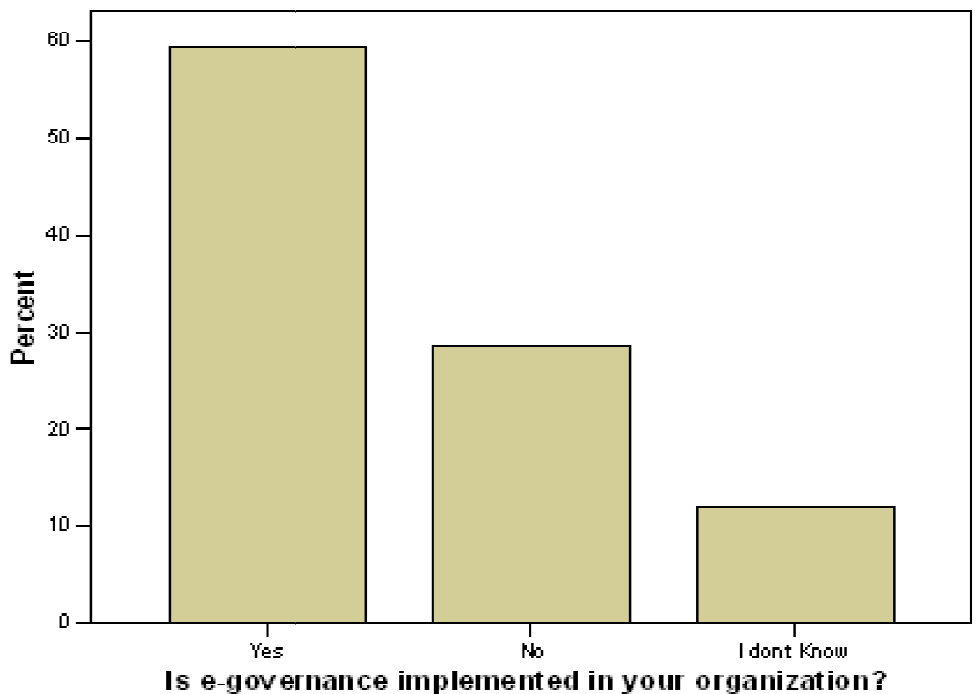

Figure 3: Staff Opinion on Implementation of E-Governance in Their Organization

These results indicated that most of the citizens and staff are familiar with e-governance and e-government services. It also showed that government agencies were implementing e-government service delivery as president's directive (Directorate of e-government, Kenya, 2009). Citizens who were familiar with e-governance and e-government are those who either use e-government services or are aware of the e-government services offered through their departments or agencies.

\subsection{Communication Medium for Accessing E-Government Service in Kenya}

The study also sought to establish the medium of communication mostly used in offering access to e-government services in the Kenya. This study found that Websites and email are the commonly used medium of communication used by government agencies to offer services to the citizens and employees online. A cumulative percentage of $86.9 \%$ of the respondents admitted that websites, blogs and email are the widely used medium of communication as shown in table 2 below. Of the respondents, $38.1 \%$ indicated that websites and blogs are used as medium of communication and $48.8 \%$ indicated that e-mails were being used in their organization.

\begin{tabular}{|c|c|c|c|c|c|}
\hline \multicolumn{2}{|c|}{} & Frequency & Percent & $\begin{array}{c}\text { Valid } \\
\text { Percent }\end{array}$ & $\begin{array}{c}\text { Cumulative } \\
\text { Percent }\end{array}$ \\
\hline Valid & Website and blogs & 32 & 38.1 & 38.1 & 38.1 \\
\hline & E-mail & 41 & 48.8 & 48.8 & 86.9 \\
\hline & Sort Message Service (SMS) & 2 & 2.4 & 2.4 & 89.3 \\
\hline & Phone Calls & 8 & 9.5 & 9.5 & 98.8 \\
\hline & Others.... & 1 & 1.2 & 1.2 & 100.0 \\
\hline & Total & 84 & 100.0 & 100.0 & \\
\hline
\end{tabular}

Table 2: Medium of Communication Used in E-Governance

This indicated that email tool was the widely used for communication. The findings in this study concurred with Siebel (2005) who opined that most of the governments and government agencies offer e-government services through the Internet. This means that information in the government departments and agencies is published on websites for employees to access and conveyed through email. This is an indication that the web-based model of e-government was widely used in Kenya.

\subsection{Effectiveness of the E-Government Models Used in Kenya}

The study sought to establish the effectiveness of the e-government models used in Kenya through the communication medium used by citizens in accessing e-government services. Among the respondents, $11.1 \%$ strongly agreed and $12.5 \%$ agreed that the communication medium they used to access that email was effective and efficient. However, a majority of the respondents comprising of $72.2 \%$ disagreed and $1.4 \%$ strongly disagreed that the medium was effective as shown in table 3 below. 


\begin{tabular}{|c|c|c|c|c|c|c|c|c|c|c|}
\hline & \multicolumn{2}{|c|}{ Strongly Agree } & \multicolumn{2}{c|}{ Agree } & \multicolumn{2}{c|}{ Not sure } & \multicolumn{2}{c|}{ Disagree } & \multicolumn{2}{c|}{ Strongly Disagree } \\
\hline & Count & $\%$ & Count & $\%$ & Count & $\%$ & Count & $\%$ & Count & $\%$ \\
\hline $\begin{array}{c}\text { Communication } \\
\text { medium used in } \\
\text { my organization is } \\
\text { effective }\end{array}$ & 8 & $11.1 \%$ & 9 & $12.5 \%$ & 2 & $2.8 \%$ & 52 & $72.2 \%$ & 1 & $1.4 \%$ \\
\end{tabular}

Table 3: Effectiveness of Communication Medium Used to Access E-Government Services

These results indicated that web-based e-government service delivery through email was not approved by majority of the citizens in Kenya and were efficient. Layne\& Lee (2001) opined that the shortcomings of the web-based egovernment models should be addressed. This suggested that government agencies should adopt the emerging technologies like the SMS-based e-government models to offer services to their clients.

\subsection{Reliability of the E-Government Models Used in Kenya}

The study sought to establish the reliability of the e-government models through establishing the communication medium used in the government agencies in Kenya. The study results showed that $11.3 \%$ and $26.8 \%$ of the respondents strongly agreed and agreed respectively that the communication medium that was being used to offer e-government services was reliable. A majority of the respondents $53.5 \%$ disagreed and $1.4 \%$ strongly disagreed on the reliability of the communication medium they used to access online services from their organization.

\begin{tabular}{|c|c|c|c|c|c|c|c|c|c|c|}
\hline & \multicolumn{2}{|c|}{ Strongly Agree } & \multicolumn{2}{|c|}{ Agree } & \multicolumn{2}{|c|}{ Not sure } & \multicolumn{2}{|c|}{ Disagree } & \multicolumn{2}{|c|}{$\begin{array}{l}\text { Strongly } \\
\text { Disagree }\end{array}$} \\
\hline & Count & $\%$ & Count & $\%$ & Count & $\%$ & Count & $\%$ & Count & $\%$ \\
\hline $\begin{array}{c}\text { The } \\
\text { communicatio } \\
\mathrm{n} \text { medium } \\
\text { used in my } \\
\text { organization } \\
\text { is reliable }\end{array}$ & 8 & $11.3 \%$ & 19 & $26.8 \%$ & 5 & $7.0 \%$ & 38 & $53.5 \%$ & 1 & $1.4 \%$ \\
\hline
\end{tabular}

Table 4: Effectiveness and Reliability of the Communication Tool

The findings here indicated that the reliability issues of the web-based e-government models like slow speed, delayed access and delayed feedback to the users need to be addressed Layne \& Lee (2001). This could be done by adopting emerging communication medium and hence e-government models that are reliable in accessing e-government models.

\section{Conclusion}

The study concluded that government agencies in Kenya such as the University of Nairobi offered e-government services such as access to information, online applications and downloading of government documents to citizens; staff; businesses entities and to other government agencies. It was established that Web-based e-government model implemented using websites and email systems was the mostly used e-government model. However, the systems used for implementation were ineffective and unreliable. This was attributed to the fact that the systems provided static information (Backus, 2001), did not provide instant feedback (Rusdiah, 2003) and depend on Internet (Ndou, 2004) whose infrastructure in the country is poor. This hinders or delays access to e-government services offered.

\section{Recommendation}

This study made the following recommendations:

- Governments should adopt e-government technologies that are effective and that provide instant feedback to the users

- Government should consider implementing our country wide Internet infrastructure and lower the cost of accessing it

- Integration of both web-based and SMS-based e-government models to enhance access to e-government services

- Further studies with the aim of designing and developing e-government systems that reap from the benefits of the web-based and SMS-based models to enhance service delivery.

\section{References}

i. Backus, M. (2001). E-governance in developing countries. IICD Research Brief, Vol. 1. March 2001.

ii. Baum, H. \& Maio, A. (2000). Gartner's Four Phases of E-government Model. http://www.gartner.com [accessed September10, 2009].

iii. Directorate of e-government. (2009). Kenya e-government, accessed on July 14, 2009 http://www.egovernment.go.ke .

iv. Heeks, R. (2001). Understanding e-governance for development. E-Government Working Paper Series.http://idpm.man.ac.uk/idpm/igov11.htm. Accessed on 25/01/2010. 
v. Layne, K. \& Lee, J. (2001). Developing fully functional E-government: A four stage model.Government Information Quarterly, vol. 18, no. 2, pp. 122(15).

vi. Nonyongo, E. Mabusela, K.\& Monene, V. (2007). Effectiveness of SMS Communication between University and Students. University of South Africa, South Africa.

vii. Ndou, V. (2004). E-government for Developing Countries: Opportunities and Challenges. The Electronic Journal on Information Systems in Developing Countries (EJISDC) No 18.

viii. Siebel, (2002). E-government in Europe: Transforming Public Service with Constituent -Centric Technology. http://www.keelan.ie/uploads/documents/Document_Library/WP_eGov.pdf. Accessed 15/9/2009.

ix. Rusdiah, R., (2003). Lebarnya Jurang E-government. EBizz Asia, Volume I no. 10. http://www.ebizzasia.com/0110- 2003/egov,0110,01.htm. Accessed 17/9/2009.

x. Susanto, T.\& Goodwin, R.(2006). Implementing SMS-based e-Government Model. 8 $^{\text {th }}$ International Conference on Information Integration and Web-based Applications\& Services, Yogyakarta.

xi. Susanto,T.\& Goodwin, R. (2010). Factors Influencing Citizen Adoption of SMS-Based e-Government Services. Electronic Journal of e-Government Volume 8 Issue 1 2010, (pp55 - 71), accessed on 28/09/2009, http:// www.ejeg.com .

xii. Susanto, T.\& Goodwin, R. (2007). Content Presentation \& SMS-based eGovernment.http://repository.gunadarma.ac.ke.id:800/I-24_1731.pdf. Accessed on 22/9/2009.

xiii. World Bank Report. (2005). E-Development: From Excitement to Effectiveness. The International Bank for Reconstruction and Development / The World Bank.http://documents.worldbank.org/curated/en/261151468325237852/pdf/341470EDevelopment.pdf. Accessed on 12/10/2009.

xiv. Susanto, T., Goodwin, R. \& Paul, C. (2008). A six-level model of SMS-based E-Government. International Conference on E-Government (ICEG),Australia. http://smsegov.info/images/smsegov.pdf . Accessed 18/10/2009. 